\title{
BMJ Open Receiving the home care service offered by certified care workers prior to a patients' death and the probability of a home death: observational research using an instrumental variable method from Japan
}

Kazuhiro Abe, ${ }^{1}$ Atsushi Miyawaki, ${ }^{1}$ Yasuki Kobayashi, ${ }^{1}$ Haruko Noguchi, ${ }^{2}$ Hideto Takahashi, ${ }^{3}$ Nanako Tamiya ${ }^{4}$

To cite: Abe K, Miyawaki A, Kobayashi Y, et al. Receiving the home care service offered by certified care workers prior to a patients' death and the probability of a home death: observational research using an instrumental variable method from Japan. BMJ Open 2019;9:e026238. doi:10.1136/ bmjopen-2018-026238

- Prepublication history and additional material for this paper are available online. To view these files, please visit the journal online (http://dx.doi. org/10.1136/bmjopen-2018026238).

Received 23 August 2018 Revised 26 July 2019 Accepted 26 July 2019
Check for updates

(C) Author(s) (or their employer(s)) 2019. Re-use permitted under CC BY-NC. No commercial re-use. See rights and permissions. Published by BMJ.

For numbered affiliations see end of article.

Correspondence to Dr Kazuhiro Abe;

kazuhiro.abe.1215@gmail.com

\section{ABSTRACT}

Objectives To assess the association between receiving the certified care workers' home care service, which is provided by non-medical professionals prior to a patients' death and the probability of a home death.

Design Observational research using the full-time translated number of certified care workers providing home care service per member of the population aged 65 or above, during the year prior to patient's death per municipality as an instrumental variable.

Setting The certified care workers' home care service covered by the public long-term care insurance (LTCl) system in Japan.

Participants In total, 1613391 LTCI beneficiaries aged 65 or above who passed away, except by an external cause of death, between January 2010 and December 2013 were included in the analysis.

Primary outcome measures Death at home or death at other places, including hospitals, nursing homes and clinics with beds.

Results Out of all participants, 173498 (10.8\%) died at home. The number of patients who used the certified care workers' home care service more than once per each month during 1, 2 or 3 months prior to the month of death numbered 213848,176686 and 155716 , respectively. This was associated with an increased probability of death at home by $9.1 \%$ points $(95 \% \mathrm{Cl} 2.9$ to 15.3$)$, $10.5 \%$ points (3.3 to 17.6 ) and $11.4 \%$ points (3.6 to 19.2), respectively.

Conclusions The use of the certified care workers' home care service prior to death was associated with the increased probability of a home death.

\section{INTRODUCTION}

Age structures across the world are expected to change significantly over the next few decades. In most regions of the world, nearly a quarter of the population will be 60 years of age or older by $2050 .{ }^{1}$ Along with this change, long-term care systems are required
Strengths and limitations of this study

- This is the first study that suggests the association between receiving the home care service by non-medical professionals and the increased probability of a patients' home death.

- The analysis is conducted using the combined nationwide large-scale data of the public long-term care insurance claims data and vital statistics in Japan.

- An instrumental variable analysis is performed to address confounding attributed to preferences for the death place of unobserved patients or patients' families, assuming the exclusion restrictions after the adjustments.

- Our estimates obtained by the instrumental variable regression might be the local average treatment effect.

- Although all the study participants received longterm care services, the home deaths in our study might have included some unintentional and unattended deaths because of the limitation of vital statistics.

in many counties to support the elderly who are spending the end of their lives in their preferred places for their satisfaction. ${ }^{2}{ }^{3}$ Most elderly people wish to die at home, and their families' satisfaction would be much improved if an environment that allows them to take care of themselves at the end of their lives in their preferred places is arranged. ${ }^{45}$ However, they often die in other places, such as hospitals, due to the burden of care on the families and the uneasiness of the care recipients. ${ }^{6-9}$ Social and health policies to ensure more elderly people can die at home are expected to develop in the near future. 
Previous studies have reported that death at home was associated with patients' illness (long-term disease, low functional status and having cancer); individual factors (good socioeconomic conditions, preferences of care recipients) and environmental factors (use of home care services by physicians and nurses, the use of multidisciplinary home palliative care, the timing of the introduction of palliative care, living in a rural environment and the presence of informal caregivers including spouse and relatives, informal caregivers' coping and historical trends). ${ }^{10}{ }^{11}$ However, these associations do not necessarily indicate that using home care services leads to home death because unobserved patients' and their families' preferences for the place of death cannot be adjusted for appropriately. ${ }^{10-12}$ Additionally, some previous studies suffered from a limited generalisability because they have focused only on patients with cancer. ${ }^{10}$ With regard to the palliative care services at home, several randomised controlled trials have demonstrated its effectiveness on home death for adults with advanced illness. ${ }^{13}$ However, in those studies, multidisciplinary home palliative care teams consisted mainly of physicians, nurses and medical social workers, and did not include care workers who were not medical professionals. Therefore, the effectiveness of home care services offered by care workers prior to home death remains unknown. During the end of life, the burden of care for informal caregivers is among a serious issue. ${ }^{9}$ The home care service offered by care workers at the end of life could support informal caregivers, such as patients' families, as well as mitigate caregivers' burdens, and increase the possibility of death at home.

This research aimed to assess the association between receiving the home care service by care workers prior to a death and the probability of a home death. To address the endogeneity in the use of home care services caused by unobserved patients' and their families' preferences for the place of death, an instrumental variable (IV) method was used.

\section{Background in Japan}

Gaps in the place where people die

In 2012, a nationwide survey conducted in Japan, one of the most rapidly ageing societies in the world, revealed that elderly people are more likely to expect spending their life's last moments at home instead of hospitals and facilities; $34.9 \%$ of elderly people wanted long-term care delivered at home and $54.6 \%$ wanted to die at home. ${ }^{14}$ In 1951, the proportion of home deaths was $82.5 \%$ and the proportion of hospital deaths only $9.1 \%$. However, in 2017, the proportion of home deaths had reduced to $13.2 \%$ and the proportion of hospital deaths had increased to $73.0 \% .^{6}$ Thus, there is a huge gap between the preferred place and actual place of death.

\section{Home care services in Japan}

In Japan, certified care workers' home care service has provided assistance to care recipients with the activities of daily living (ADL) and the instrumental ADL (IADL). Care workers need to complete a 130-hour training programme to obtain certification. Certified care workers' home care service is covered by public long-term care insurance (LTCI). LTCI was initiated by the Japanese government in 2000, with compulsory participation. ${ }^{15}$ Those aged over 40 and are suffering from intractable diseases and those aged over 65, requiring care, are eligible to receive long-term care services with small copayments $(10 \%$ of actual expenses). LTCI covers various services other than the certified care workers' home care service; including day-care services, a home nursing service by qualified nurses, a home physiotherapeutic service and residential care services.

\section{METHODS \\ Data}

We targeted LTCI beneficiaries aged 65 or above who passed away, excluding deaths caused by external factors such as accidents or suicide (V01-Y89 on the International Classification of Diseases 10 (2003)), between January 2010 and December 2013. A pooled cross-sectional study was deployed. With official approval to use the secondary data from the Statistics and Information Department of the Japanese Ministry of Health, Labour and Welfare (MHLW) under Tohatsu-1218-1 as of 18 December 2015, we used the individual data from the Survey of Long-term Care Benefit Expenditures, the death records from Vital Statistics, the Survey of Medical Institutions and the Survey of Institutions and Establishments for Long-term Care. ${ }^{16}$ In addition, we also used the aggregated data from the population census and municipal taxation published by the Japanese government. ${ }^{17} 18$ Since all individual data were anonymised by the MHLW, we could not identify a specific individual. As individual data did not include the common number for each person, we conducted a deterministic linkage between the Survey of Long-term Care Benefit Expenditures and the death records from Vital Statistics using five items of demographic data to identify death for each LTCI beneficiary; prefectures, municipalities, sex, month and year of birth and month and year of death. Although the date of death is not included in the Survey of Long-term Care Benefit Expenditures, the eligibility for LTCI expires exactly 1 day after the date of death on the death certification. Thus, we matched the data indicating the month and year of the patient's death to the month and year of the day before LTCI eligibility expiry's date. The deterministic linkage revealed that $15.3 \%$ of the five items of demographic verification data were overlapped between all expiry dates of LTCI eligibility because the exact date of the patient's birth and death were not included in the data of each of the Survey of Long-term Care Benefit Expenditures and death record. We excluded those samples from the analysis. Also, the expiry of LTCI eligibility includes those who have moved to other municipalities, as well as death. Thus, the linkage between the Survey of Long-term Care Benefit Expenditures and Vital 
Statistics was $81.3 \%$ (18.7\% of LTCI eligibility expiry did not match $1: 1) .{ }^{19}$ We excluded the unmatched samples from the analysis. Finally, we extracted the data for those LTCI beneficiaries who passed away at the age of 65 or more between January 2010 and December 2013.

\section{Outcome, exposure and IV}

The outcome was patients' death at home. The other places of death included hospitals, nursing homes and clinics with beds. The primary exposure was the use of certified care workers' home care service more than once during the month prior to the month of death. This service is included in home nursing care services in the classification of healthcare products of the System of Health Accounts 2011 and was revised by Organisation for Economic Co-operation and Development, European Union and World Health Organization in 2017. ${ }^{20}$ To cope with the endogeneity of the primary exposure, we conducted an IV regression analysis. The full-time translated number of certified care workers providing home care service per member of the population aged 65 or above, during the year prior to death per each municipality, was used as an IV. The number of fulltime conversions was calculated by adding the number of full-time home care workers, full-time converted number of concurrent home care workers and full-time converted number of part-time home care workers for each municipality. Unemployed home care workers, who are still seeking job opportunity, were excluded. It was expected that the use of home care services would increase if the patient lived in a municipality with many certified care workers because care recipients would have more opportunities to use the home care service. It was further expected that patients would live in a municipality irrespective of patients' or their family's preference for a place of death. The number of home care workers within a municipality in the year before patient's death was supposed to be exogenous to the relationship between the primary exposure and the outcome through adjustments in individual-level and municipality-level factors as proxies of the unobserved municipality-level preference for death at home. Namely, it was assumed that the number of home care workers within a municipality in the year before patient's death would increase the probability of a home death through the use of the home care service, after adjusting for the covariates shown below (an exclusion restriction). In the next section, we explain in detail the potential confounders adjusted for.

\section{Other covariates}

\section{IIIness and individual factors}

By referring to determinants of the place of death in previous studies, the patients' age at the time of death, sex, presence of spouse (presence, unmarried, bereavement and divorce), the underlying cause of death (dummy variables of cancer (C00-C97), cerebrovascular disease (I60-I69), cardiovascular disease (I01, I020,
I05-I09, I20-I25, I27 and I30-I52), senility (R54) and pneumonia (J12-J18)), the year of death, the degree of care need were adjusted as illness and individual factors. The underlying cause of death was based on the International Classification of Diseases 10 (2003). ${ }^{21}$ In Japan, the degree of care needed is classified into seven stages. It includes two stages that require support of the IADL (levels 1 and 2) and five that require long-term care of the ADL (levels 1-5). The higher the level is, the more is the need for care. ${ }^{22}$ We used the dummy variable of care needed and divided them into the three categories: a low degree including level 1 and 2 requiring IADL support, a moderate degree including level 1 and 2 requiring support for a part of the ADL, and the high degree including levels 3-5 requiring support for all ADLs. The database used to identify each variable is indicated in online supplementary table S1.

\section{Environmental factors}

Adjustment variables related to environmental factors included the following data from municipal area as well as administrative districts: the population, the proportion of population aged over 65 , the crude death rate of those aged over 65 years, the proportion of solitary elderly households, the proportion of elderly couple households and the annual income per capita and the number of beds in hospitals, clinics, home care support clinics, home-visit nursing stations and beds of nursing homes per member of the population aged over 65 . The crude death rate was calculated by dividing the number of deaths of those over 65 by the number of people aged 65 or over. The proportion of solitary elderly households was the proportion of households where an elderly aged over 65 lives alone, occupying the total number of general households. In addition, the proportion of elderly couple households referred to the proportion of households with one male aged over 65 and one female aged over 60 per the total number of general households. The home care support clinic runs 24 hours and provides home medical care from doctors and qualified nurses, in collaboration with other hospitals and clinics in the area. The database used to identify each regional variable is indicated in online supplementary table S1. These data were linked to the extracted target individual data by the municipal code of the place of residence. In addition, as a patient's behaviour may differ depending on the presence of secondary medical areas, the dummy variables of 330 secondary medical areas were adjusted. Definitions of secondary medical areas are set by the Japanese government to secure patients' access to inpatient services. Most of them are based on a complex of adjacent municipalities. We assumed that these adjustments would resolve the instrument-outcome confounders. There were no missing values in any of the variables. However, there were some unknown codes indicating the care level and the presence of the spouse. They were excluded from the analysis. 


\section{Statistical analysis}

We conducted a two-stage least squares (2SLS) regression analysis. ${ }^{23}$ We supposed the following two equations:

$$
\begin{aligned}
& y_{1 i}=x_{1 i} \pi_{1}+x_{2 i} \pi_{2}+\varepsilon_{i} \\
& y_{2 i}=y_{1 i} \beta_{1}+x_{1 i} \beta_{2}+\mu_{i}
\end{aligned}
$$

Here, $y_{1 i}$ indicates use of certified care workers' home care service 1 month prior to the month of death, which becomes 1 if $i$-th person used the service and 0 if person did not use the service; $y_{2 i}$ is an indicator of home death, which becomes 1 if $i$-th person died at home and 0 if person died in another place; $x_{1 i}$ indicates $i$-th person's age, sex, degree of care need, presence of spouse, underlying cause of death, year of death, secondary medical area dummy variables and data from the living municipality; including the population, proportion of population of those aged over 65, crude death rate of those aged over 65 , the proportion of solitary elderly households, the proportion of elderly couple households, annual income per capita, the number of beds in hospitals, clinics, home care support clinics, home-visit nursing stations and beds of nursing homes per member of the population aged over 65. Meanwhile, $x_{2 i}$ is an IV, which indicates the fulltime translated number of certified home care workers in a living municipality a year prior to the patient's death. $\beta$ and $\pi$ are coefficients of each variable. $\varepsilon$ and $\mu$ are error terms.

During the first stage, we estimated $\hat{y}_{1 i}$ (the fitted values of $y_{1 i}$ ) by an ordinary least squares (OLS) estimation using the equation (1). During the second stage, we regressed $y_{2 i}$ on $\hat{y}_{1 i}$ and $x_{1 i}$ by the following OLS estimation:

$$
y_{2 i}=\hat{y}_{1 i} \beta_{1}+x_{1 i} \beta_{2}+\left\{\left(y_{1 i}-\hat{y}_{1 i}\right) \beta_{1}+\mu_{i}\right\}
$$

which was transformation of the equation (2). The resulting estimator $\hat{\beta}_{1}$ is consistent for $\beta_{1}$ if $x_{2 i}$ is uncorrelated with $\mu_{i}$ conditioned by $x_{1 i}$. This implies that if the exclusion restriction stated above is valid, the resulting estimator is consistent for $\beta_{1}$. Since we had a large number of observations through 2SLS, a linear probability model could be practically used even for a dichotomous variable such as an indicator of home death, the distribution of which would be normal asymptotically. ${ }^{24}$ Robust SEs were estimated. $\hat{\beta}_{1}$ indicated the effect of the use of home healthcare prior to death based on the probability of death at home, and is reported in the results section.

The Kleibergen-Papp Wald rk F statistic checked the weak identification of IV. In this study, since an endogenous variable was exactly identified by an IV, overidentification test of IV was not conducted. The endogeneity of the exposure variable was assessed by the Wooldridge's robust score $\chi^{2}$ test and robust regression-based $\mathrm{F}$ test. An OLS estimation for equation (2) with robust SEs was also conducted for comparison with the 2SLS approach result. The analyses were repeated using 'at least one use of the home care service every month during the 2 or 3 months prior to the month of death' as the exposure.
Data management and analysis were all conducted using Stata V.14 MP with the ivreg2 package. ${ }^{25}$

\section{Patient and public involvement}

This research was done without any patient involvement. Patients were neither invited to comment on the study design nor consulted to develop patient-relevant outcomes or interpret the results. Further, patients were not invited to contribute to the writing or editing of this document for readability or accuracy.

\section{RESULTS}

There were 1716065 LTCI beneficiaries who passed away between January 2010 and December 2013. After excluding patients with those aged under 65 , extrinsic death, unknown care levels and those whose spouse's presence remained unknown, 1613391 patients were analysed. This totalled $37.7 \%$ of all deaths of those aged over 65 in Japan, throughout the 4 years studied.

Table 1 shows the characteristics of illness and individual factors of the participants by place of death. The proportion of home deaths was around $10.8 \%$ irrespective of the year of death. The number of those who used home care services at least once prior to the month of death totalled 213848 patients or $13.3 \%$ of the population. The proportions of home death were $8.2 \%$ for those who did not use the home care service and $27.3 \%$ for those who used it prior to the month of their death. A summary of the municipal data used as an IV and covariates is presented in table 2 .

In the first stage, Kleibergen-Paap Wald rk F statistic was 752.7, which was much higher than 10 (the 'rule of thumb' value).$^{26}$ The results of the first stage of the 2SLS are presented in online supplementary table S2. As expected, the higher the number of certified home care workers per member of the population aged over 65 in a municipality, the likelihood for the use home care services increased.

Table 3 presents the results of the association between the certified care workers' home care service use prior to death and the probability of a home death, using the OLS and the 2SLS. The use of home care services 1 month prior to death was associated with an increased probability of home death in either analysis: $\hat{\beta}_{1}=0.180 ; 95 \%$ CI 0.178 to 0.182 in the OLS; $\hat{\beta}_{1}=0.091 ; 95 \%$ CI 0.029 to 0.153 in the 2SLS. The use of the home care services 1 month prior to the death increased the probability of death at home by $9.1 \%$ points according to the IV regression. The 2SLS analyses were repeated for the use of services during 2 and 3 months prior to the month of death as exposures. The $\hat{\beta}_{1}$ s were slightly higher than for home care service use during the month prior to death as an exposure $\left(\hat{\beta}_{1}=0.105 ; 95 \%\right.$ CI 0.033 to 0.176 for 2 months use prior to the month of death; $\hat{\beta}_{1}=0.114 ; 95 \%$ CI 0.036 to 0.192 for 3 months use prior to the month of death, respectively). The differences between the OLS estimates 
Table 1 The characteristics of illness and individual factors of long-term care beneficiaries ( $<65$ years old) who died, excluding death by external factors, between 2010 and 2013 by place of death

\begin{tabular}{|c|c|c|c|c|c|}
\hline \multirow{2}{*}{$\begin{array}{l}\text { Characteristics } \\
\text { No of death }\end{array}$} & \multicolumn{2}{|l|}{ Home } & \multicolumn{2}{|c|}{ Other places* } & \multirow{2}{*}{$\begin{array}{l}\text { Total } \\
1613391\end{array}$} \\
\hline & 173498 & $10.8 \%$ & 1439893 & $89.3 \%$ & \\
\hline Median (IQR) age, years & $86(80-91)$ & & $86(80-92)$ & & $86(80-92$ \\
\hline \multicolumn{6}{|l|}{ Sex } \\
\hline Male & 77443 & $10.8 \%$ & 641915 & $89.2 \%$ & 719358 \\
\hline Female & 96055 & $10.7 \%$ & 797978 & $89.3 \%$ & 894033 \\
\hline \multicolumn{6}{|l|}{ No of death by year } \\
\hline 2010 & 44564 & $10.8 \%$ & 368721 & $89.2 \%$ & 413285 \\
\hline 2011 & 41589 & $10.6 \%$ & 351673 & $89.4 \%$ & 393262 \\
\hline 2012 & 45583 & $10.9 \%$ & 372223 & $89.1 \%$ & 417806 \\
\hline 2013 & 41762 & $10.7 \%$ & 347276 & $89.3 \%$ & 389038 \\
\hline \multicolumn{6}{|l|}{ Degree of care need } \\
\hline Low & 11071 & $13.9 \%$ & 68451 & $86.1 \%$ & 79522 \\
\hline Moderate & 40643 & $12.8 \%$ & 278066 & $87.2 \%$ & 318709 \\
\hline High & 121784 & $10.0 \%$ & 1093376 & $90.0 \%$ & 1215160 \\
\hline \multicolumn{6}{|c|}{ No of the use of certified care workers' home care service prior to death } \\
\hline No use & 115078 & $8.2 \%$ & 1284465 & $91.8 \%$ & 1399543 \\
\hline 1 month & 58420 & $27.3 \%$ & 155428 & $72.7 \%$ & 213848 \\
\hline 2 months & 47026 & $26.6 \%$ & 129660 & $73.4 \%$ & 176686 \\
\hline 3 months & 41618 & $26.7 \%$ & 114098 & $73.3 \%$ & 155716 \\
\hline \multicolumn{6}{|l|}{ Presence of spouse } \\
\hline Present & 72677 & $11.4 \%$ & 566300 & $88.6 \%$ & 638977 \\
\hline Unmarried & 5000 & $9.1 \%$ & 50044 & $90.9 \%$ & 55044 \\
\hline Bereavement & 89471 & $10.4 \%$ & 766788 & $89.6 \%$ & 856259 \\
\hline Divorce & 6350 & $10.1 \%$ & 56761 & $89.9 \%$ & 63111 \\
\hline \multicolumn{6}{|l|}{ Underlying cause of death } \\
\hline Cancer & 49083 & $13.2 \%$ & 323426 & $86.8 \%$ & 372509 \\
\hline Pneumonia & 7054 & $3.2 \%$ & 212692 & $96.8 \%$ & 219746 \\
\hline Cerebrovascular & 15886 & $8.5 \%$ & 170040 & $91.5 \%$ & 185926 \\
\hline Senility & 24850 & $19.8 \%$ & 100346 & $80.2 \%$ & 125196 \\
\hline Cardiovascular & 21828 & $24.2 \%$ & 68421 & $75.8 \%$ & 90249 \\
\hline Others & 54797 & $8.8 \%$ & 564968 & $91.2 \%$ & 619765 \\
\hline
\end{tabular}

${ }^{*}$ Other places include the deaths at the hospitals, clinics with beds and nursing homes.

and 2SLS estimates and the Wooldridge's robust score $\chi^{2}$ test $8.03(\mathrm{p}=0.018)$ and robust regression-based $\mathrm{F}$ test 8.03 $(\mathrm{p}=0.005)$ showed the endogeneity between exposure and outcome. Online supplementary table S3 presents these results including the covariates of the OLS regression and IV regression.

\section{DISCUSSIONS}

\section{Principal findings}

This study demonstrated that the use of the certified care workers' home care service prior to death was positively associated with the probability of a home death among LTCI beneficiaries. When the IV can address the endogeneity in the relationship between the use of home care services and home death, our findings suggest that at the individual level, the use of home care services for 1,2 or 3 months prior to the month of death increase the probability of death at home by $9.5 \%, 10.9 \%$ and $11.9 \%$, respectively. The estimates might be essential when considering the current proportion (13.2\% in 2017) of home deaths in Japan.

\section{Comparison with other studies and strengths of this study}

Most previous studies in various countries, including Japan, have examined the association between home care services provided by medical professionals such as physicians, nurses and medical social workers and home 
Table 2 Summary of municipal data used as an instrument variable and covariates $(n=1695)$

\begin{tabular}{|c|c|c|c|}
\hline & $\begin{array}{l}\text { 25th } \\
\text { percentile }\end{array}$ & Median & $\begin{array}{l}\text { 75th } \\
\text { percentile }\end{array}$ \\
\hline Population* & 8.815 & 25.419 & 67.197 \\
\hline $\begin{array}{l}\text { Proportion of } \\
\text { population aged over } \\
65\end{array}$ & 0.223 & 0.272 & 0.322 \\
\hline $\begin{array}{l}\text { Crude death rate of } \\
\text { those aged over } 65 \\
\text { years } †\end{array}$ & 0.030 & 0.035 & 0.039 \\
\hline $\begin{array}{l}\text { Proportion of solitary } \\
\text { elderly household }\end{array}$ & 0.074 & 0.096 & 0.130 \\
\hline $\begin{array}{l}\text { Proportion of elderly } \\
\text { couple household }\end{array}$ & 0.096 & 0.118 & 0.148 \\
\hline $\begin{array}{l}\text { Annual income per } \\
\text { capitał }\end{array}$ & 24.728 & 26.770 & 29.821 \\
\hline $\begin{array}{l}\text { No of beds in } \\
\text { hospitals§ }\end{array}$ & 0.010 & 0.037 & 0.062 \\
\hline No of clinics & 1.906 & 2.557 & 3.226 \\
\hline $\begin{array}{l}\text { No of home care } \\
\text { support clinics } \|\end{array}$ & 0 & 0.267 & 0.519 \\
\hline $\begin{array}{l}\text { No of home-visit } \\
\text { nursing stations }\end{array}$ & 0 & 0.132 & 0.229 \\
\hline $\begin{array}{l}\text { No of beds in nursing } \\
\text { homes§ }\end{array}$ & 0.021 & 0.030 & 0.040 \\
\hline $\begin{array}{l}\text { Full-time translated } \\
\text { no of certified home } \\
\text { care workers } \S^{\star \star}\end{array}$ & 0.015 & 0.026 & 0.039 \\
\hline
\end{tabular}

*Per 1000 people.

†Calculated by dividing the number of deaths of those over 65 by the number of people aged 65 or over.

$\ddagger$ Per 100000 JPY (about €750, US\$1000).

$\S$ Per population aged over 65 years.

१Per 1000 population aged over 65 years.

${ }^{\star *}$ Calculated by adding the number of full-time home care workers, full-time converted number of concurrent home care workers and full-time converted number of part-time home care workers for each municipality.

death. ${ }^{10-13}$ However, there have been few investigations of the health outcomes of services provided by non-medical professionals. ${ }^{27}$ A study in Japan reported the association between the use of welfare services, including home care services by non-medical professionals and home death in $1990 .^{28}$ This study would not be suitable for the current situation in Japan as it was conducted 10 years prior to the introduction of LTCI. In addition, several studies have reported an association between the use of certified care workers' home care services and an improvement of the patients' and families' satisfaction and maintenance of patients' ADL, ${ }^{29-32}$ but they did not include the place of death as an outcome. This study can claim originality due to the examination of the association between the use of the certified care workers' home care service by non-medical professionals and the place of patients' death, using
Table 3 The results of the association between the certified care workers' home care service use and the probability of a home death by each term of continuous use prior to death, using ordinary least squares (OLS) regression and two-stage least squares (2SLS) regression ( $n=1613$ 391)

\begin{tabular}{clll}
\hline & Coefficient & Robust SE & $\mathbf{9 5 \%} \mathbf{C l}$ \\
\hline $\begin{array}{c}\text { 1 month } \\
\text { OLS }\end{array}$ & 0.1796 & 0.0010 & 0.1777 to 0.1815 \\
\hline 2SLS & 0.0908 & 0.0315 & 0.0291 to 0.1525 \\
\hline 2 months & & & \\
\hline OLS & 0.1672 & 0.0011 & 0.1651 to 0.1693 \\
\hline 2SLS & 0.1049 & 0.0364 & 0.0334 to 0.1763 \\
\hline 3 months & & & \\
\hline OLS & 0.1661 & 0.0011 & 0.1639 to 0.1683 \\
\hline 2SLS & 0.1138 & 0.0396 & 0.0362 to 0.1915 \\
\hline
\end{tabular}

nationwide large-scale data extracted from the public LTCI system. Although this was an observational study, we managed to address endogeneity in the use of care services attributed to unobserved patients' or patient families' preferences for the place of death by using the IV method.

\section{Possible mechanism}

According to a survey conducted in 2017 , over $70 \%$ of the elderly people in Japan worry that their families will be burdened should they receive long-term care at home. ${ }^{9}$ A few studies have demonstrated that the use of the certified care workers' home care service is associated with a reduction in the psychological caregiving burden of patients' families, ${ }^{29}$ and made patients feel secure and confident about their lives, by providing physical assistance with their ADL and IADL. ${ }^{32}$ Thus, the use of certified care workers' home care services prior to death might assist terminal patients to die at home, both by reducing families' caregiving burden and by relieving care recipients' uneasiness.

\section{Limitations}

Some limitations should be noted. First, the home deaths recorded in this study might have included some unintentional and unattended deaths. Although we could not detect such situations from death records, we supposed that most patients and their informal caregivers in this study were in receipt of the appropriate medical and long-term care services at the end of life because they had applied to the LTCI, were using the long-term care services to some degree and were not deaths caused by external factors.

Second, the IV method used in the current study was based on the assumption of exclusion restriction. To justify this assumption, we adjusted for as many factors that could confound between the IV and patients' place of death as possible, as shown in the Methods section. Nevertheless, if our analyses still suffered from the 
violation of exclusion restriction caused by insufficient adjustment for the factors that connected the IV and the outcome, our estimates might be biassed to some degree.

Third, the estimates obtained by the IV regression might be the local average treatment effect. Namely, our IV estimates suggested the average effect of change in the use of home care services induced by a change in the number of home care workers employed in the municipality. Thus, we cannot conclude the effectiveness of the certified care workers' home care service on home death of always takers, never takers and defiers, even if the number of certified care workers in the municipality increases. ${ }^{33}$ Moreover, the estimates might include the interaction effects with other home care services. Considering the heterogeneity of service effect on the place of death, it would be necessary to study each demographic.

\section{Implications}

Our findings suggest that the use of certified care workers' home care service prior to death is associated with the increased probability of death at home. Policy-makers should ensure that elderly patients who wish to die at home have sufficient opportunities to use the care workers' home care service at the end of life.

\section{CONCLUSION AND FUTURE RESEARCH}

The use of the certified care workers' home care service prior to death was associated with the higher likelihood of patients' home death. Future research should investigate the effectiveness of other long-term care services on the place of death in a super-ageing society; including physiotherapeutic services, day-care services and residential care services, such as respite care services.

\section{Author affiliations}

${ }^{1}$ Department of Public Health, Graduate School of Medicine, The University of Tokyo, Tokyo, Japan

${ }^{2}$ Faculty of Political Science and Economics, Waseda University, Tokyo, Japan ${ }^{3}$ National Institute of Public Health, Wako, Japan

${ }^{4}$ Department of Health Services Research, Faculty of Medicine, University of Tsukuba, Tsukuba, Japan

Contributors KA conceived the study. KA and AM wrote the first and successive drafts of the manuscript. KA, AM, YK and HN contributed to study's conception, design and modelling. $K A$ and $H N$ contributed to data management and analysis. $\mathrm{HN}$, HT and NT collected the data. All authors revised the manuscript for important intellectual content. All authors had full access to the data and take responsibility for the integrity of the data and the accuracy of the data analysis. YK is the guarantor.

Funding This work was supported by the Japanese Ministry of Health, Labour and Welfare grant number H27-seisaku-senryaku-012, the Japan Society for the Promotion of Science grant number 18H03021 and the Japan Agency for Medical Research and Development grant number JP18dk0110026. The Japanese Ministry of Health, Labour and Welfare approved the secondary use of the data for this study (approval no. 1218-1).

Disclaimer The funders had no role in the design and conduct of the study; management, analysis and interpretation of the data and preparation, review or approval of this manuscript.

Competing interests None declared.

Patient consent for publication Not required.
Ethics approval The Ethics Review Committees of the University of Tokyo (approval no. 11070-1) and the University of Tsukuba (approval no. 1009).

Provenance and peer review Not commissioned; externally peer reviewed.

Data availability statement No additional data are available.

Open access This is an open access article distributed in accordance with the Creative Commons Attribution Non Commercial (CC BY-NC 4.0) license, which permits others to distribute, remix, adapt, build upon this work non-commercially, and license their derivative works on different terms, provided the original work is properly cited, appropriate credit is given, any changes made indicated, and the use is non-commercial. See: http://creativecommons.org/licenses/by-nc/4.0/.

\section{REFERENCES}

1. United Nations. World Population Prospects 2017 - Data Booklet (ST/ESA/SER.A/401)), 2017. Available: https://esa.un.org/unpd/wpp/ Publications/Files/WPP2017_DataBooklet.pdf

2. World Health Organization. Towards long-term care systems in subSaharan Africa, 2017. Available: http://www.who.int/ageing/longterm-care/en/

3. United Nations. Growing need for long-term care: assumptions and realities, 2016. Available: https://www.un.org/development/desa/ ageing/news/2016/09/briefing-paper-growing-need-for-long-termcare-assumptions-and-realities/

4. Gomes B, Calanzani N, Gysels M, et al. Heterogeneity and changes in preferences for dying at home: a systematic review. BMC Palliat Care 2013;12:7.

5. Sadler E, Hales B, Henry B, et al. Factors affecting family satisfaction with inpatient end-of-life care. PLoS One 2014;9:e110860.

6. Japanese Ministry of Health Labour and Welfare. Trends in percent distribution of deaths by place of occurrence, 2017. Available: https://www.e-stat.go.jp/en/stat-search/files?page=1\&layout= datalist\&toukei $=00450011 \&$ tstat $=000001028897 \&$ cycle $=7 \&$ year $=$ $20170 \&$ month $=0 \&$ tclass $1=000001053058 \&$ tclass $2=000001053061 \&$ tclass $3=000001053065 \&$ stat_infid $=000031749376 \&$ result_back $=1 \&$ second $2=1$

7. World Health Organization Regional Office for Europe. Palliative care for older people: better practices, 2011. Available: http://apps.who. int/iris/bitstream/handle/10665/107290/e95052.pdf;jsessionid=3D0B F82C4FA42296C864400E45B3D536? sequence $=1$

8. Bell CL, Somogyi-Zalud E, Masaki KH. Factors associated with congruence between preferred and actual place of death. J Pain Symptom Manage 2010;39:591-604.

9. Japanese Ministry of Health Labour and Welfare. The results of the survey on awareness of the elderly people about their health 2017.

10. Costa V, Earle CC, Esplen MJ, et al. The determinants of home and nursing home death: a systematic review and meta-analysis. BMC Palliat Care 2016;15:8.

11. Gomes B, Higginson IJ. Factors influencing death at home in terminally ill patients with cancer: systematic review. BMJ 2006;332:515-21.

12. Takeu R. A review of articles about factors association with death at home and death at Hospital since 1990 in Japan. Journal of Japan Academy of Community Health Nursing 2008;11:87-92.

13. Gomes B, Calanzani N, Curiale V, et al. Effectiveness and costeffectiveness of home palliative care services for adults with advanced illness and their caregivers. Cochrane Database Syst Rev 2013;36.

14. Cabinet Office Government of Japan. The results of the survey on awareness of the elderly people about their health 2012

15. Tamiya $\mathrm{N}$, Noguchi $\mathrm{H}$, Nishi $\mathrm{A}$, et al. Population ageing and wellbeing: lessons from Japan's long-term care insurance policy. The Lancet 2011;378:1183-92.

16. Japanese Ministry of Health Labor and Welfare. List of statistical surveys conducted by Ministry of health, labour and welfare, 2016. Available: http://www.mhlw.go.jp/toukei/itiran/eiyaku.html

17. Japanese Ministry of Internal Affairs and Communications. Population census. Available: http://www.stat.go.jp/english/data/ kokusei/index.htm

18. Japanese Ministry of Internal Affairs and Communications. Survey of municipal taxation. Available: http://www.soumu.go.jp/main sosiki/ jichi_zeisei/czaisei/czaisei_seido/ichiran09.html

19. Noguchi $\mathrm{H}$. Exploring the utilization of administrative data in Japan : Focusing on the long-term care claims data. trends in modern economics 2017-Japanese economic association 2017:99-126

20. OECD/Eurostat/WHO. A system of health accounts 2011: OECD publishing, 2017 
21. Japanese Ministry of Health Labor and Welfare. Table of ICD-10 (2003) codes on the cause of death. Available: http://www.mhlw.go. jp/toukei/sippei/xls/shiin2003.xls

22. Sakamoto H, Rahman M, Nomura S, et al. Japan Health System Review. In: World Health organization regional office for south-east Asia. New Delhi, 2018: 136-7.

23. Wooldridge JM. Econometric analysis of cross section and panel data. The MIT Press, 2010.

24. Angrist JD, Pischke J-S. Mostly harmless Econometrics: an Empiricist's companion. Princeton Univ PR, 2008.

25. Stillman S. "IVREG2: Stata module for extended instrumental variables/2SLS and GMM estimation," Statistical Software Components: Boston College Department of Economics, 2002. Available: https://ideas.repec.org/c/boc/bocode/s425401.html

26. Stock J, Yogo M. Testing for Weak Instruments in Linear IV Regression. In: Donald WKA, ed. Identification and inference for Econometric models. New York: Cambridge University Press, 2005: 80-108.

27. Hatoma A. Systematic review on outcome assessment of home care service. Japanese Journal of Gerontology 2015;37:295-305.
28. Tamiya N, Araki S, Kawakami N, et al. [Factors affecting death at home in bedridden elderly people]. Nihon Koshu Eisei Zasshi 1990;37:33-8.

29. Tsutsui T. Influence of the use of home services on family care burden of family caregiver. Home-visit nursing and nursing care 2010;15:630-9.

30. Matsumoto T, Nekoda Y. Analysis on the effect of using the longterm care insurance service for prevention against deterioration of degree of care level. Journal of health and welfare statistics 2009;56:20-6.

31. Kim J, Hiraoka K. Changes and influence factors in physical and mental functions of elderly people requiring care at home. Journal of health and welfare statistics 2004;51:8-15.

32. Hayasaka T, Mitadera Y. Evaluation of home welfare services by the elderly person himself. Journal of health and welfare statistics 2003;50:8-16.

33. Imbens WG, Rubin BD. Instrumental variables analysis of randomized experiments with two sided Noncompliance. causal inference in statistics, social, and biomedical sciences: an introduction. Cambridge University Press, 2015: 542-59. 